\title{
River Discharge Estimation based on Satellite Water Extent and Topography: An Application over the Amazon
}

\author{
DINH THI LAN ANH \\ Sorbonne Université, Observatoire de Paris, Université PSL, CNRS, LERMA, Paris, France, \\ and University of Science and Technology of Hanoi, Hanoi, Vietnam \\ FILIPE AIRES \\ Sorbonne Université, Observatoire de Paris, Université PSL, CNRS, LERMA, and Estellus, Paris, France
}

(Manuscript received 26 September 2018, in final form 23 June 2019)

\begin{abstract}
River discharge (RD) estimates are necessary for many applications, including water management, flood risk, and water cycle studies. Satellite-derived long-term GIEMS-D3 surface water extent (SWE) maps and HydroSHEDS data, at 90-m resolution, are here used to estimate several hydrological quantities at a monthly time scale over a few selected locations within the Amazon basin. Two methods are first presented to derive the water level (WL): the "hypsometric curve" and the "histogram cutoff" approaches at an $18 \mathrm{~km} \times 18 \mathrm{~km}$ resolution. The obtained WL values are interpolated over the whole water mask using a bilinear interpolation. The two methods give similar results and validation with altimetry is satisfactory, with a correlation ranging from 0.72 to 0.89 in the seven considered stations over three rivers (i.e., Wingu, Negro, and Solimoes Rivers). River width (RW) and water volume change (WVC) are also estimated. WVC is evaluated with GRACE total water storage change, and correlations range from 0.77 to 0.88 . A neural network (NN) statistical model is then used to estimate the RD based on four predictors (SWE, WL, WVC, and RW) and on in situ RD measurements. Results compare well to in situ measurements with a correlation of about 0.97 for the raw data (and 0.84 for the anomalies). The presented methodologies show the potential of historical satellite data (the combination of SWE with topography) to help estimate RD. Our study focuses here on a large river in the Amazon basin at a monthly scale; additional analyses would be required for other rivers, including smaller ones, in different environments, and at higher temporal scale.
\end{abstract}

\section{Introduction}

River discharge (RD) estimation is important for both scientific (e.g., water cycle analysis, land/ocean freshwater exchanges) and operational reasons (e.g., flood risk, water management). Unfortunately, the number of publicly available in situ measurement stations has decreased in recent decades (Wahl et al. 1995), in particular in developing countries. This is a major drawback for hydrology because in addition to being direct, continuous, and potentially very precise measurements of the $\mathrm{RD}$, in situ measurements are also very important to calibrate the indirect measurements or hydrological models.

Satellite observations have the advantage of being available globally, regardless of national borders, often at a daily scale, and sometimes over long time series.

Corresponding author: Filipe Aires, filipe.aires@obspm.fr
Currently, the volume of available satellite data grows exponentially with time and instruments have an increased spatial resolution. In fact, satellite observations do not observe the RD directly, but they provide reasonable estimates of surface water extent (SWE) that increase with the river water flow. As a result, estimating RD based on SWE could give reasonable results compared to methods based on water level (WL) measurements (Ashmore and Sauks 2006).

Several types of satellite observations can be used, each with their own advantages and limitations. Synthetic aperture radar (SAR) has a high spatial resolution (Smith et al. 2007). For example, Sentinel-1 now provides high spatial (from $5 \mathrm{~m} \times 5 \mathrm{~m}$ to $20 \mathrm{~m} \times 40 \mathrm{~m}$ depending on the acquisition mode) and temporal resolution SAR data. In principle, SAR data have a spatial resolution compatible with the monitoring of small rivers but the retrieval of surface waters under vegetation is still an issue, and until 
now, only sparse data were available. Furthermore, temporal resolution was not adequate for temporal monitoring since only a few snapshots were typically available over a particular region. Optical sensors have been used to estimate RD (Brakenridge et al. 2005; Gleason et al. 2014). For instance, the methodology introduced in Brakenridge et al. (2007) is also used by Tarpanelli et al. (2013) to retrieve discharge estimation at a daily scale using Moderate Resolution Imaging Spectroradiometer (MODIS) data. Similarly, Gleason et al. (2014) have used Landsat TM images with a 30-m spatial resolution.

Passive microwave observations have also been used to monitor the RD. For instance, Brakenridge et al. (2007) have developed an algorithm based on the ratio of the radiance of two pixels (i.e., over and outside the river) which has been used in the Global Flood Detection System (http://old.gdacs.org/flooddetection/overview.aspx). Other approaches use a measure of the SWE directly (Smith 1997). However, in comparison to infrared and visible observations, passive microwave observations have a coarser spatial resolution. Therefore, deriving RD directly from microwave observations is difficult. Passive microwave information provides an area-based measure instead of a distance-based measure on the river. Such a measure of SWE over a coarse-scale box can integrate several strategic locations such as inside bends of meandering rivers, islands coasts, etc. This type of spatially integrative information can be used to estimate the RD.

In this paper, we propose another way of using passive microwave observations to estimate the RD by combining SWE estimation with topographical information instead of using the radiance ratio. This use of passive microwave data is made possible by considering first a downscaling scheme to increase the SWE spatial resolution. Here, a downscaling of the GIEMS-D3 dataset [Global Inundation Extent from Multi-Satellites (GIEMS) from $25 \mathrm{~km}$ to $3 \operatorname{arcs}(90 \mathrm{~m}$ )] (Aires et al. 2017) is considered instead of the original GIEMS based on two main arguments. First, it is possible to test the ability of high-spatial inundation information [potentially from other instruments such as Surface Water and Ocean Topography (SWOT)] to estimate the RD. Second, we can derive different quantities from the SWE [such as the WL, river width (RW), or water volume change (WVC)] that could complement the water extent. As in Bjerklie et al. (2003), the approach presented here is based on a statistical model that links hydraulic observations and RD measurements. Various combinations of potentially observable variables (SWE, WL, RW, and WVC) have been tested to estimate the RD.

Section 2 presents the datasets that are used in this work. The methodologies are introduced in section 3 . Results are provided in section 4, and conclusions are gathered in section 5 together with some perspectives.

\section{Datasets}

\section{a. Surface water extent from GIEMS-D3}

A multisensor technique has been developed to estimate SWE at a global scale (Prigent et al. 2007) from 1993 to 2007 at the monthly time scale. It benefits from the complementary sensitivities of different satellite observations to surface characteristics (e.g., water, vegetation, soil) to minimize limitations and uncertainties related to measurements by individual instruments. Passive microwave observations are particularly sensitive to the presence of surface water, even under vegetation canopy. However, additional observations have to be used to subtract, from the signal, the contribution of confounding factors such as vegetation and to avoid confusion with other surface types such as dry sand. The following satellite observations were used to generate GIEMS: 1) passive microwaves from the Special Sensor Microwave/Imager (SSM/I) measurements between 19 and $85 \mathrm{GHz} ; 2$ ) active microwave backscattering coefficients at $5.25 \mathrm{GHz}$ from the European Remote Sensing (ERS) satellite scatterometers; and 3) the Advanced Very High Resolution Radiometer (AVHRR) visible $(0.58-0.68 \mathrm{~mm})$ and near-IR $(0.73-1.1 \mathrm{~mm})$ reflectances and the derived normalized difference vegetation index (NDVI). The methodology is described in detail in Prigent et al. (2001). Note that the GIEMS estimates include all surface waters such as rivers, lakes, flooded areas, and rice paddies. The inundation is expressed as the fractional inundation within each $773 \mathrm{~km}^{2}$ pixel of the equal-area grid (with a $0.25^{\circ}$ resolution at the equator). Regional assessment of this database using SAR data indicates that this approach realistically captures wetland complexes but can underestimate small wetlands comprising less than $10 \%$ fractional coverage of a grid cell $\left(<80 \mathrm{~km}^{2}\right)$, or overestimate wetlands of more than $90 \%$ of fractional coverage due to its coarse spatial resolution. GIEMS is available to the scientific community under request (see http://lerma.obspm.fr/ spip.php?article91lang=en).

To increase the spatial resolution of global inundation estimates, downscaling techniques have been applied to GIEMS (Aires et al. 2013, 2014; Fluet-Chouinard et al. 2015). In particular, in Aires et al. (2017), a downscaling methodology based on the topographical information from Hydrological Data and Maps Based on Shuttle Elevation Derivatives at Multiple Scales (HydroSHEDS; see the following section) was proposed to obtain GIEMS-D3, a global and dynamic inundation dataset, at high spatial resolution $(\sim 90 \mathrm{~m}=3$ arc s), over 15 years with a monthly time step. This dataset was compared to another global inundation dataset in Aires et al. (2018). It is shown that visible-based datasets such as Landsat 
products (Pekel et al. 2016; Yamazaki et al. 2015) are the best solution to monitor permanent waters (river, lakes, etc.) but that they drastically underestimate transitory waters such as wetlands. GIEMS and GIEMS-D3, by using passive microwave data, are less sensitive to vegetation presence and provide good information about these transitory waters. Therefore, a combination of visible and passive microwave data should be developed in the future. Also, the combination with SAR data should improve even further our monitoring of inundated surfaces.

GIEMS-D3 results from the downscaling at $90 \mathrm{~m}$ of GIEMS by using a floodability index that was based on a neural network (NN) model of the flooding probability. This model used several types of topographical information (i.e., distance to river, slope, elevation above the closest river, etc.) from the HydroSHEDS data. The downscaling scheme has been improved compared to GIEMS-D15 (Fluet-Chouinard et al. 2015), with an updated smoothing procedure, a better extrapolation for coastal areas, and a higher spatial resolution.

\section{b. Topographical information from HydroSHEDS}

The HydroSHEDS project (http://www.hydrosheds.org) provides a digital elevation model (DEM) and a suite of hydrographic parameters derived from the Shuttle Radar Tropical Mission (SRTM) dataset at resolutions ranging from 3 arc s to $5 \mathrm{~min}$, in a consistent format from $56^{\circ} \mathrm{S}$ to $60^{\circ} \mathrm{N}$ (Lehner et al. 2008). The HydroSHEDS hydrologic conditioning smooths sampling errors that interrupt the flow and hydrographic connectivity in the original SRTM DEM. In this study, we use HydroSHEDS data to construct: 1) hypsographic curves and 2) elevation histograms of inundated and noninundated pixels (see section 2a) which can then be used to estimate the WL. However, we cannot obtain elevations below the water when measurements were done by SRTM due to the lack of bathymetric information in HydroSHEDS data. Unfortunately, this is a substantial limitation for many hydrologic applications using topographic data.

\section{c. Altimetry data from ENVISAT}

WL is measured by several satellite altimetry missions such as TOPEX/Poseidon (1992-2006), GFO (1998-2008), Jason-1 (2001-13), Jason-2 (2008-present), and Jason-3 (2016-present). Here, we consider the altimetry data from ENVISAT (2002-12) which has 35-day temporal resolution and $80 \mathrm{~km}$ equatorial intertrack spacing. The data have been processed by the Laboratoire d'Etudes en Geodésie et Océanographie Spatiales (LEGOS), in coordination with the HYDROWEB project, providing WL variations for about 150 lakes and reservoirs, and about 2382 points over the 38 major rivers around the world
(Cretaux et al. 2011) (freely available at http:// hydroweb.theia-land.fr/). Note that no calibration toward in situ data has been done in these datasets.

We obtained the ENVISAT altimetry data of some virtual stations at the intersection between the satellite tracks and the considered rivers, over the Amazon basin. These data are then used to compare and evaluate our estimation of the WL. GIEMS-D3 provides data from 1993 to 2007, while the altimetry data are available from 2003 to present. As a result, the WL estimates are evaluated only in the 5-yr overlap period between 2003 and 2007. In this study, among the available ENVISAT Virtual Stations (VS), we chose seven of them for the comparison with the WL estimation in Table 1 and Fig. 7. This work is expected to be extended to all available VS over the Amazon.

\section{d. Total water storage from GRACE}

The Gravity Recovery and Climate Experiment (GRACE) mission (Tapley et al. 2004) is one of the most significant missions of the NASA Earth System Science Pathfinder (ESSP) program. It provides the measurements of Earth's gravity field anomalies from its launch in March 2002 to the end of its science mission in October 2017. These gravity anomalies are then converted into the total water storage anomalies at a $300-\mathrm{km}$ spatial resolution, which highlight variations of mass concentrations in a region. The gravity variations can be used to estimate the groundwater storage changes. The GRACE total water storage estimates can be downloaded at https:// grace.jpl.nasa.gov/data/get-data/monthly-mass-grids-land/ (Landerer and Swenson 2012). The data from the CSR solution of GRACE will be used in the following for validation and comparison with our estimates of the WVC.

\section{e. In situ river discharge}

In situ RD data are provided by the Global Runoff Data Centre (GRDC), which is an international archive of data up to 200 years old. GRDC provides data over 9300 stations in 160 countries (available at http:// www.bafg.de/GRDC). Although the number of publicly available measurements has not ceased to decrease in the last decades for political and economic reasons (Wahl et al. 1995) at the global scale, there are numerous available data over the Amazon region. The example of the Manacapuru station $\left(3.50^{\circ} \mathrm{S}-57.35^{\circ} \mathrm{W}\right)$ in situ RD data will be presented from 1998 to 2007 in section 4c.

\section{Methods}

\section{a. Water level estimation}

The WL estimations are based on the combination of two satellite datasets: the inundation extent from 
TABLE 1. Correlation between the WL estimates (raw/anomaly of the original/calibrated data) and the altimetry data, over the seven virtual stations, during the $2003-08$ period.

\begin{tabular}{llcccccc}
\hline \hline No. & River & Lat & Lon & GIEMS-D3 WL & Calibrated WL & Anomalies WL & Anomalies of calibrated WL \\
\hline 1.1 & Xingu & $-3.50^{\circ}$ & $-52.27^{\circ}$ & 0.89 & 0.92 & 0.39 & 0.40 \\
1.2 & Negro & $-0.33^{\circ}$ & $-63.75^{\circ}$ & 0.76 & 0.80 & 0.61 & 0.61 \\
1.3 & Negro & $-1.92^{\circ}$ & $-61.35^{\circ}$ & 0.82 & 0.83 & 0.51 & 0.52 \\
1.4 & Negro & $-2.08^{\circ}$ & $-61.21^{\circ}$ & 0.72 & 0.79 & 0.34 & 0.35 \\
1.5 & Solimoes & $-3.61^{\circ}$ & $-61.00^{\circ}$ & 0.84 & 0.89 & 0.62 & 0.75 \\
1.6 & Solimoes & $-3.85^{\circ}$ & $-62.49^{\circ}$ & 0.86 & 0.86 & 0.70 & 0.71 \\
1.7 & Solimoes & $-3.82^{\circ}$ & $-63.92^{\circ}$ & 0.85 & 0.86 & 0.68 & \\
\hline
\end{tabular}

GIEMS-D3 and the topography from HydroSHEDS. The approach is divided into three steps described in the following subsections.

\section{1) Preprocessing of THE SWE FROM GIEMS-D3}

To estimate the WL from the GIEMS-D3, the SWE needs to be coherent with the HydroSHEDS dataset. Because of some mismatches found in the combination of GIEMS-D3 and the topographical map, a SWE preprocessing step has to be applied to increase this coherency. Ideally, the same elevation should be found along the river edges on the same neighborhood. In fact, the GIEMS-D3 downscaling has been performed using not only the elevation but also other multiple topographic variables, in order to capture the flooding dynamics of areas such as wetlands that are not as easy to delineate as rivers. As a result, the elevation could be enough for this specific work over the rivers in this study. The preprocessing step could use the elevation information from HydroSHEDS directly.

In this step, several window boxes were tested in an empirical way such that: the number of pixels in these boxes needs to be big enough to have smooth cumulative distribution function (CDF) or probability density function (PDF) (used in the following hypsometric or histogram approaches), but be small enough to be representative of the local conditions. The actual threshold has been determined by trial-and-error analysis; it corresponds to a moving window of $150 \times 150$ pixels. The preprocessing step consists in allocating the same GIEMS-D3 percentage of inundation in the box to the same percentage of the lowest pixels from the HydroSHEDS data. This step does not affect the spatial patterns of the GIEMS-D3 inundation very much, but it shows the difference in the marginal parts, for example, the edges of the rivers. This correction makes the SWE maps from GIEMS-D3 more coherent with the topographical maps from HydroSHEDS. Ideally, the same elevation should be found along the river edges inside the $150 \times 150$ pixel moving window.
The GIEMS-D3 downscaling is expected to be improved in the future by using a better topography (Yamazaki et al. 2017). For the specific task of estimating the WL, we expect that more direct use of the topographical information should help to focus on rivers instead of wetlands. Thus, this preprocessing step might not be required in the future. Furthermore, when a mission such as SWOT (Prigent et al. 2016; Desai et al. 2018) provides good high-resolution water maps, this preprocessing step might again not be needed anymore, but tests must be conducted to ensure that SWOT will be able to detect surface waters beneath vegetation.

\section{2) Two WL estimation Methodologies}

The preprocessed SWE and the topographical information are now combined to estimate the WL. There is no need to estimate the WL on all the inundated pixels because of the following:

1) The WL estimation can be limited to the river edges where the topographical information is located.

2) GIEMS is less reliable (i.e., overestimation) over areas with a high percentage of inundation (Papa et al. 2013), so the WL estimation is here limited to inundated areas $\leq 65 \%$ (higher fractions are for pixels mostly inside the river). Low inundated areas could also be avoided (due to higher uncertainties for inundated areas $\leq 10 \%$, see section $2 \mathrm{a}$ ).

3) In the future, other filters could be applied to limit the WL estimation only on reliable pixels: for instance with a slope not too small or too high [for instance, slope $\left.s\left(\mathrm{~m} \mathrm{~m}^{-1}\right): 0.1 \leq s \leq 1\right]$.

\section{(i) Method 1: Hypsographic curve approach}

The first approach uses topography to construct a hypsographic curve that links the SWE to the WL. In Papa et al. (2013), this method was used at the $0.25^{\circ}$ $(\simeq 25 \mathrm{~km})$ resolution of the original GIEMS dataset. Here, we use the full resolution of the GIEMS-D3 dataset $(90 \mathrm{~m})$ instead. The hypsographic curve approach has two main steps summarized here: 
(a)

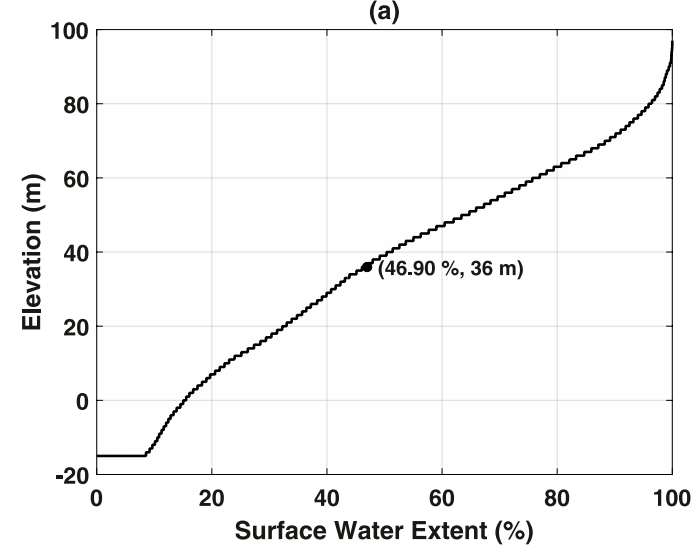

(b)

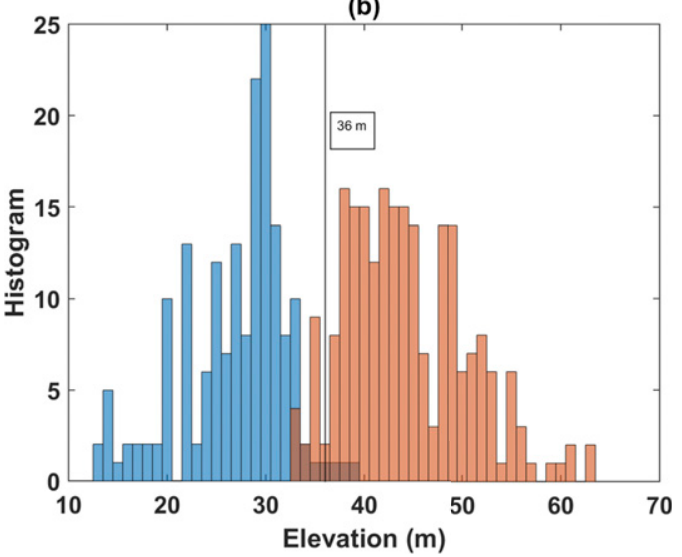

FIG. 1. Elevation estimation for January 2003 from GIEMS-D3 SWE estimate over the Rio Marau River $\left(3.75^{\circ} \mathrm{S}, 57.35^{\circ} \mathrm{W}\right)$. (a) Example of a hypsographic curve from topographic data for the $50 \times 50$ pixel window surrounding the pixel. (b) Elevation histograms in the $20 \times 20$ pixel window surrounding the pixel. Inundated (blue) and noninundated (orange) histograms are separated by an optimal vertical threshold indicating the estimated WL.

- The first step is to build the hypsographic curves using the topographic dataset. The hypsometric curve is the $\mathrm{CDF}$ of elevations in a geographical area. As explained in the preprocessing step, this area requires a suitable size to show a smooth CDF and stay close to the local conditions of the GIEMS-D3 resolution. The ensemble of elevation values from topographic dataset are gathered on a $50 \times 50$ pixel window surrounding a central pixel. The choice of this box size has been made by comparing results with different boxes from $10 \times 10$ to $70 \times 70$ pixels. A too-small box has not enough reliable WL estimates and results are not robust. On the other hand, a too-big box shows that the statistics performed in the domain are less relevant to the considered central pixel. A good compromise needs to be found based on the stability of the solution. In our experiments, this was obtained with a box of size $50 \times 50$ pixels. An automatic procedure could be put in place to obtain objective parameters for each one of the methodologies based on the stability of their results, which could be investigated in the future.

- These 2500 elevations are then ordered from the lowest to the highest value. Figure 1 shows an example of a hypsographic curve surrounding one central pixel from the chosen area. The assumption that lower elevations get inundated first allows using these curves to link SWE area (on the horizontal axis) to the WL (on the vertical axis).

- When these hypsographic curves are built from the topographical information once and for all, the WL in each pixel of the study domain can be obtained by using the corresponding inundation percentage from GIEMS-D3 in the box area. For example, GIEMS-D3 indicates that $46.9 \%$ of pixels (i.e., 1173 out of a maximum of 2500 pixels) are inundated over the Rio Marau river in January 2003, which is corresponding to a WL of $36 \mathrm{~m}$ (as shown in Fig. 1a). Therefore, the WL at the pixel $\left(3.50^{\circ} \mathrm{S}-57.35^{\circ} \mathrm{W}\right)$ for January 2003 is estimated to be $36 \mathrm{~m}$.

\section{(ii) Method 2: Histogram-cutoff approach}

We introduce another approach hereby named the histogram-cutoff method. A smaller $20 \times 20$ pixel window is selected for this histogram analysis. As for the previous hypsographic curve approach, there is no precise criterion for choosing this box size beside a trial and error analysis. This method includes two main steps:

- A $20 \times 20$ pixel window surrounding a central pixel is used to extract the 400 DEM elevations surrounding this pixel; each of them is classified as inundated or not for each month using the GIEMS-D3 SWE for that particular month (January 2003). The inundated and noninundated elevation histograms are then computed (Fig. 1b).

- From these two elevation histograms, an elevation threshold value is obtained such that the inundated and noninundated pixels are separated as well as possible. This cutoff/threshold value is then chosen as the new WL for the considered pixel. In Fig. 1b, the overlap between the inundated and noninundated pixels ranges from 33 to $39 \mathrm{~m}$. The proper WL threshold is $36 \pm 3 \mathrm{~m}$, this is the same value as the hypsometric curve approach, but an uncertainty estimate is provided with this method.

Figures $2 \mathrm{c}$ and $2 \mathrm{~d}$ represent the results of the two methods in an area over the Amazon region $\left(3.13^{\circ}-3.54^{\circ} \mathrm{S}\right.$, $\left.56.88^{\circ}-57.29^{\circ} \mathrm{W}\right)$. This figure shows that the two methods have a similar behavior. 
(a)

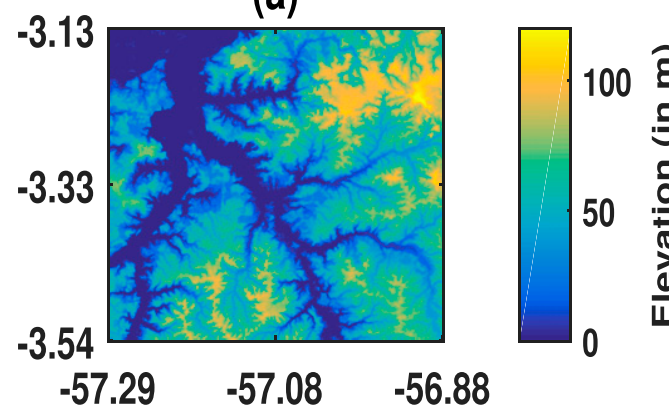

(c)
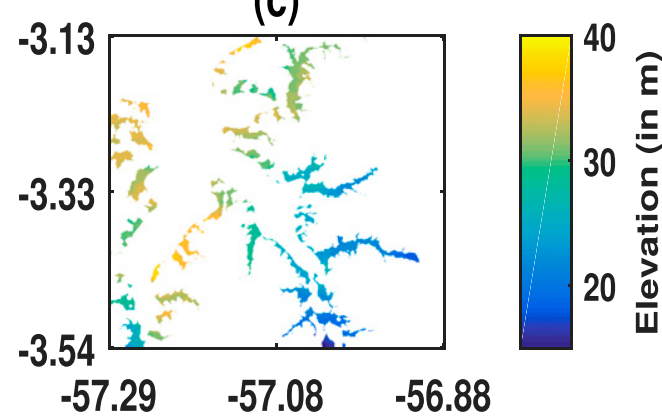

(b)

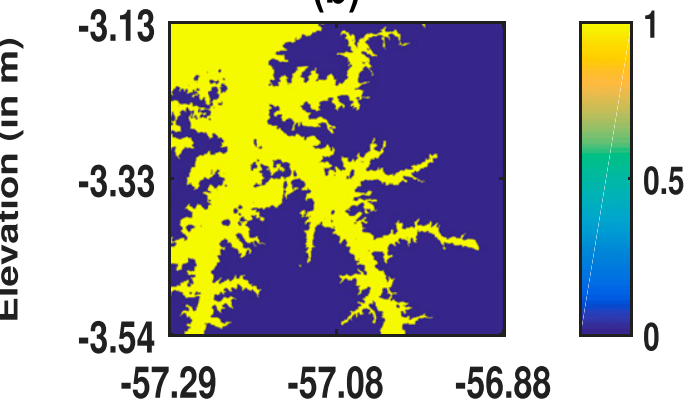

(d)

(e)

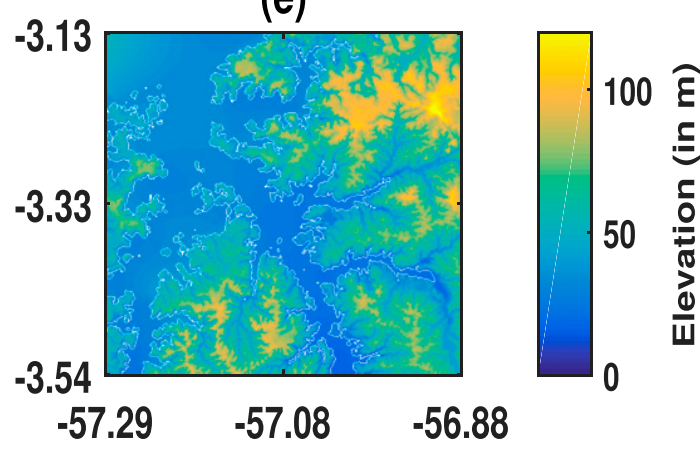

FIG. 2. Estimation of the WL $(\mathrm{m})$ in a $500 \times 500$ pixel area over the Amazon region $\left(3.13^{\circ}-3.54^{\circ} \mathrm{S}, 56.88^{\circ}-57.29^{\circ} \mathrm{W}\right)$ : (a) topography from HydroSHEDS; (b) corrected SWE from GIEMS-D3 (January 2003); (c) WL from the hypsographic curve approach; (d) WL from the histogram-cutoff approach; (e) interpolated WL map after the bilinear spatial interpolation [from WLs in (d)].

\section{3) SPATial interpolation OF THE WL}

As mentioned earlier, the WL estimation is performed only on the river or wetland edges, over "reliable" pixels. Thus, the next step is applying a bilinear interpolation to estimate the WL on all the inundated pixels. There are several advantages to this approach:

- First, by estimating the WL only in good locations (i.e., with reliable WL estimates), we can avoid erroneous WL pixels that would propagate errors in the following steps.

- Second, we also avoid using the less reliable hypsographic curves (Fig. 1a) and favor more the symmetric and less ambiguous intersecting histograms (Fig. 1b) by limiting the WL estimation on boxes with around $50 \%$ inundated fractions.

- Last, in practice, it is much faster to do the bilinear interpolation than doing the WL estimation on all the inundated pixels.

Figure 2e shows the WL bilinear interpolation results over a spatial domain in the Amazon region. These results indicate that the WL spatial interpolation is satisfactory with a smooth behavior (i.e., not too high or too low pixels) to complete the WL estimation over the whole river.

To better assess the quality of the methodology, we zoom into several smaller regions with a size of $100 \times$ 100 pixels in the study site. For instance, three smaller 

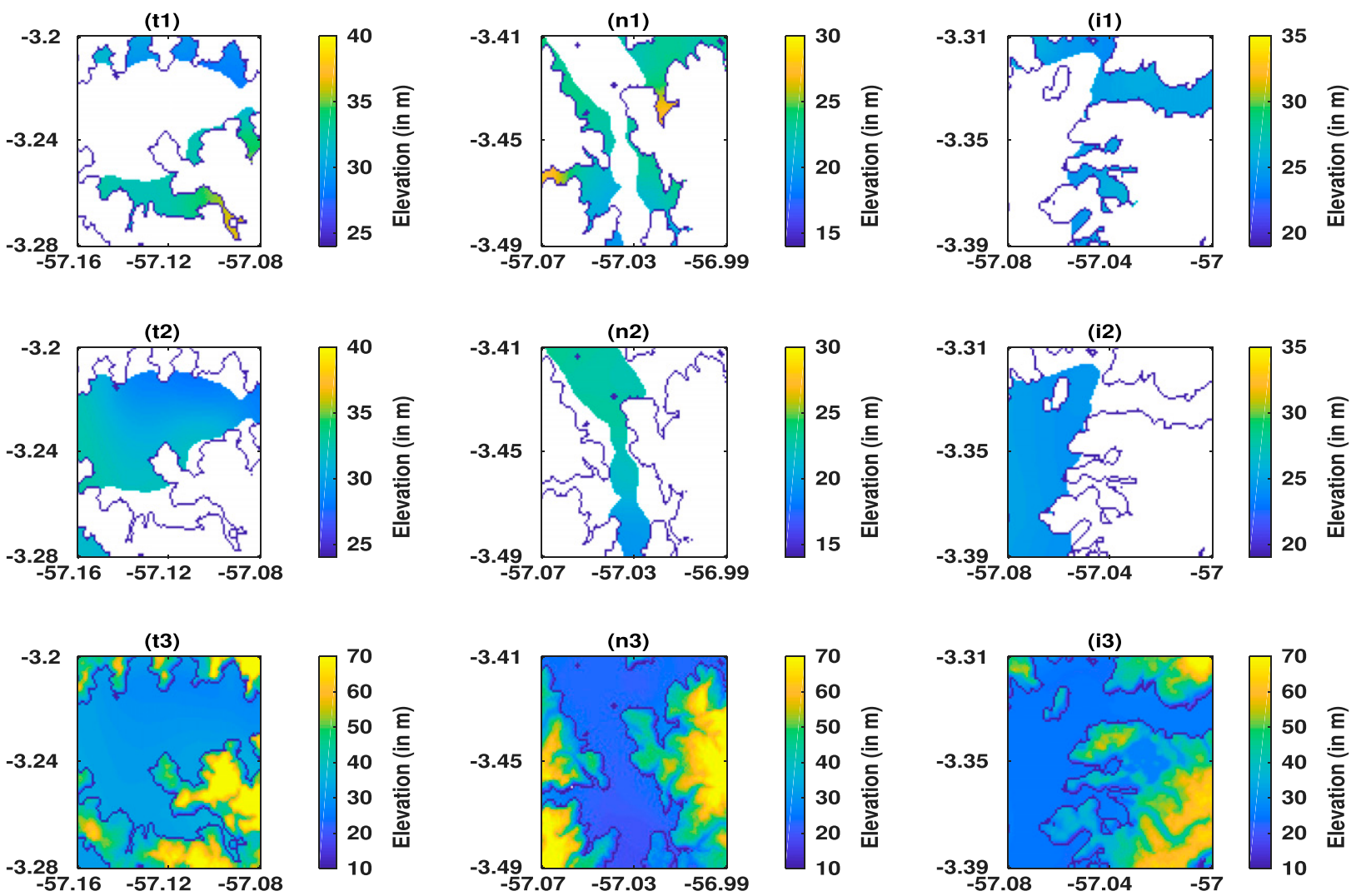

FIG. 3. Estimation of the WL $(\mathrm{m})$ in three $100 \times 100$ pixel boxes (columns): (top) WL from the histogram-cutoff approach, (middle) WL maps after the bilinear spatial interpolation, and (bottom) full maps with land topography.

areas are presented in Fig. 3 with the WL estimations from the histogram-cutoff approach (the first row), the corresponding interpolated WL map (the second row), and the complement with the land topography (the third row). This figure shows well the quality of the WL estimation and spatial interpolation. In fact, no strong gradients can be observed in the water surfaces, and the coherency with the topography over the land seems adequate.

\section{b. River width}

To estimate the $\mathrm{RW}$ on a river pixel, we first determine the flow direction based on the immediate shape of the river. After that, a line passing through this pixel is drawn perpendicularly to the river flow direction to define a river section (see Fig. 4). The RW is then computed as the number of inundated pixels in this river section, so it changes with month and inundation pattern. For each month of the GIEMS-D3 dataset (from 1993 to 2007), the number of consecutive inundated pixels in this line is defined as the RW. Each monthly SWE map from GIEMS-D3 provides a RW estimate, for each river pixel.

Since this study considers only a limited number of locations, the above processes were computed manually, but this could be automated in the future. In comparison, other studies, such as Gleason and Smith (2014), estimate "effective river width" by averaging estimated widths at multiple cross sections over an area. This process should reduce estimation uncertainties, and the obtained RW should become more significant in a discharge estimation model.

\section{c. Water volume change estimation}

The WVC over a domain can be estimated using the SWE of two consecutive months (GIEMS-D3) and the

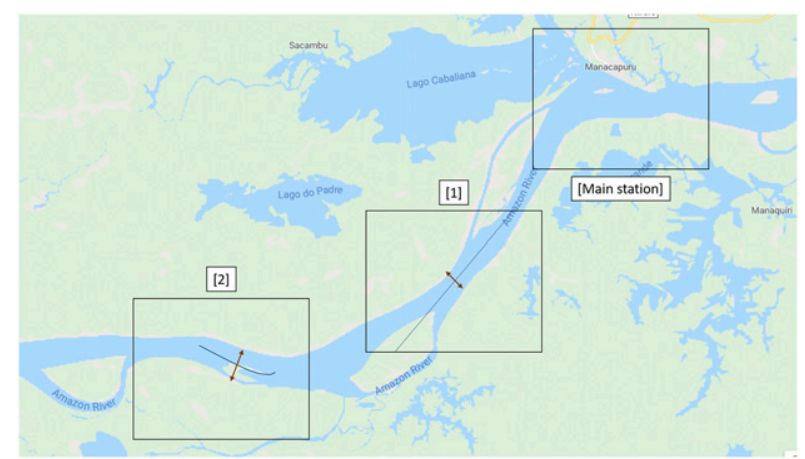

FIG. 4. Google map representing the three considered boxes centered on the river (upstream and at the Manacapuru station) to illustrate the three river width estimations. 
WLs obtained in the previous section, by using the following formula:

$$
\Delta V=\sum_{i=1}^{n}\left(\Delta h_{i}\right) \times S,
$$

where $\Delta V$ is the WVC $\left(\mathrm{km}^{3}\right)$ between two consecutive months for an area of $n$ pixels, $S$ is the area of one pixel $\left(\mathrm{km}^{2}\right)$, and $\Delta h_{i}$ is the WL change $(\mathrm{km})$ for pixel $i$ between the two consecutive months.

\section{d. River discharge estimation}

\section{1) PRedictors}

A statistical model to estimate the RD is built based on a maximum of four of the previous predictors (SWE, WL, WVC, and RW) over a $200 \times 200$ pixel box centered on the river upstream of the "main station" where the RD needs to be estimated (i.e., a station where in situ measurements are available). The box size and its location have been chosen empirically, based on a trial and error approach. Clearly, a box that is too small has a lower signal-to-noise ratio, and a box that is too big would contain nonessential information. Therefore, a good compromise needs to be found. After testing three different sizes $(100 \times 100$, $200 \times 200,300 \times 300$ ), we found that the $200 \times 200$ pixel box provided the best correlation between RD and other predictors, with a reasonable NRMSE value (not shown). Again, an automatic optimization scheme could be implemented to find the best box size and location. Furthermore, these parameters could be specific for each location. This aspect will be investigated in the future to extend the applicability of our technique.

Figure 4 represents two such boxes upstream of the station together with the main box centered on the station pixel. Tests (not shown) indicate that among these three boxes, box 1 is a better predictor for the $\mathrm{RD}$ in the main box. Thus, in the following, only box 1 will be considered. This predictive domain is one important potential parameter that would certainly require an optimization step for a more general model. For instance, in a totally different prediction approach, Brakenridge et al. (2007) and Tarpanelli et al. (2013) consider several strategic locations along the river to estimate the RD on a particular measurement station.

\section{2) LINEAR MODEL}

A linear regression method is used to model the relationship between the $\mathrm{RD}$ at a given month $e$ and one or more predictors (SWE, WL, WVC, and RW) for the same month:

$$
\begin{aligned}
\mathrm{RD}(e)= & a_{0}+a_{1} \mathrm{WE}(e)+a_{2} \mathrm{WL}(e) \\
& +a_{3} \mathrm{WVC}(e)+a_{4} \mathrm{RW}(e) .
\end{aligned}
$$

The unknown coefficients $a_{j}(j=1,2,3,4)$ are the model parameters that need to be optimized based on a dataset of samples $\mathscr{B}=\left\{\left(\mathrm{RD}^{e}, \mathrm{SWE}^{e}, \mathrm{WL}^{e}, \mathrm{VC}^{e}, \mathrm{RW}^{e}\right)\right.$; $e=1, \ldots, N\}$, where $N$ is the number of samples (i.e., number of months). Stepwise linear regression with four predictors is used to find the best model to retrieve the RD. At first, only one explanatory variable (the best one) is used to retrieve the RD. Then, at each step, a new predictor (the best additional one) is added to obtain the hierarchy of the explanatory variables.

Linear regression is used to estimate the $\mathrm{RD}$, but in order to obtain a robust quality measure, Monte Carlo cross validation is used to overcome a potential overtraining where a model performs well over the training dataset but poorly over unknown data. Therefore, the model is calibrated over $80 \%$ of the available data (i.e., training dataset), and tested over the remaining $20 \%$ data (i.e., test dataset). This test is a standard procedure in which the training algorithm optimizes the statistical model so that it performs well in the training dataset. The statistical model is then applied to the remaining testing dataset to test its performance well on data not seen during its calibration. Generally, this procedure is performed only once but results might not be robust enough if not enough data is available. In this study, we use a Monte Carlo strategy so that the testing procedure is performed 20 times, to obtain a more robust estimation of the model performance on new data.

\section{3) Neural NeTWORK MODEL}

$\mathrm{NN}$ techniques have proved very successful in developing computationally efficient statistical models for remote sensing and hydrology. It is a nonlinear mapping model: Given an input (SWE, WL, WVC, and/or $\mathrm{RW}$ ), it provides an output (the RD) in a nonlinear way. Considering the small dimension of the data here, we will use a NN model with only one hidden layer. The NN chosen in this study is a fully connected multilayer perceptron (MLP) model (Rumelhart et al. 1986) where every neuron has a connection with all the neurons of the previous layer. The MLP model is defined by the number of input neurons (i.e., the size of the inputs), the number of outputs (i.e., one here for the RD), and the number of neurons in the hidden layers that control the complexity of the model. An empirical study based on trial and error has been conducted to define the optimal number of hidden layers and the optimal number of neurons in the hidden layers. A balance needs to be found: too many free parameters in the model can result in 
overlearning leading to degraded generalization properties. On the contrary, too few free parameters will yield underparameterization and bias error of the model. We use here a NN with one hidden layer (such NNs are universal approximators of continuous functions; see Hornik et al. 1990) with 10 neurons in the hidden layer. The NN can use only one source of information when the other sources are not pertinent, or it can combine them in a nonlinear way when necessary. Complex interactions among the inputs can be exploited by the NN. As for the linear regression, it is important to address the relative stability of the training of the NN. Therefore, 20 Monte Carlo runs are used with $80 \%$ of the data for the training, and $20 \%$ for the testing.

\section{Results over the Amazon basin}

\section{a. WL evaluation using altimetry}

To evaluate the WL estimation method based on the hypsographic curve approach; our results are compared to the altimetry data of section $2 \mathrm{c}$. Several sources of discrepancies can explain the differences between these two data sources: different geoid references are used in the Hydroweb altimetry data, and the SRTM/HydroSHEDS data; a possible ENVISAT/RA2 instrument bias (Calmant et al. 2013) can exist, and most likely GIEMS-WL estimation uncertainties are also present. To facilitate the comparison and the potential assimilation of the two WL estimates, a calibration can be used to get the GIEMS-D3, and the altimetry WL estimates closer. We choose here to transform the GIEMS-D3 WL toward the altimetry data, but the opposite could be done instead. A second-order polynomial regression can be used to fit the two WLs. Figure 5 shows the results obtained over the Solimoes station 1.5, but similar results are found in the other stations.

Figure 6 represents the resulting WL time series over the Solimoes station. The top panel shows that the calibrated WL estimate follows well the dynamics of the altimetry data (correlation of 0.89 ) and that the bias between these two estimates can be reduced significantly using our simple second-order model. The anomalies are then represented and show a temporal correlation of 0.62 . However, some issues can still be observed. First, the rising and falling limbs between altimetry and GIEMSD3 estimation show a few months delay for some years (e.g., falling limb after mid-2005, or rising limb around January/February 2007). These delays can be important for water managers. There could be an issue with altimetry, but according to Santos da Silva et al. (2010), ENVISAT data on the Solimoes compare well to in situ measurements without such delay. Second, the flat values during the peak around mid-2006 for GIEMS estimation are probably due to some saturation (in GIEMS dataset

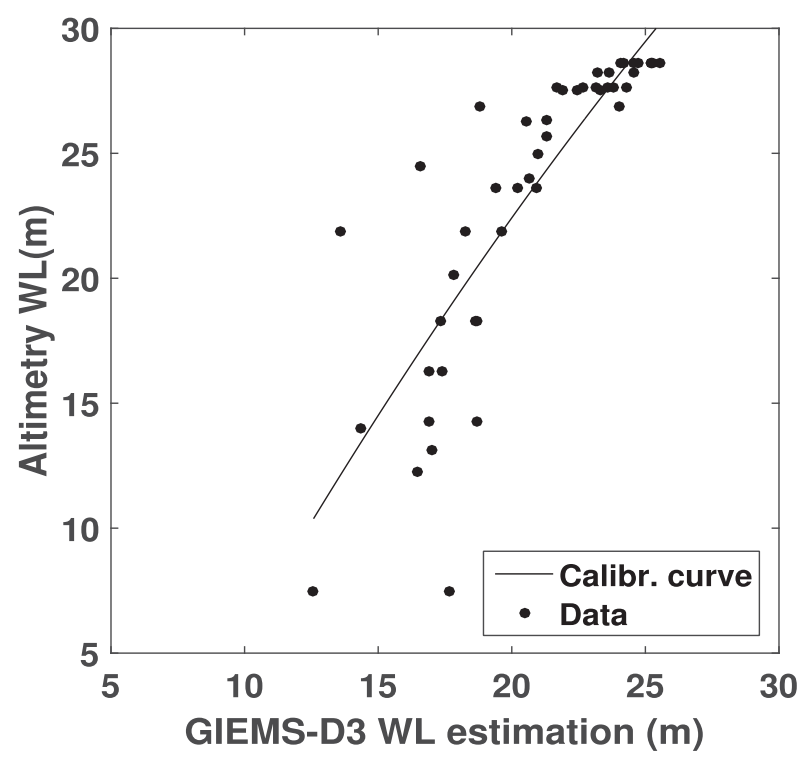

FIG. 5. Calibration of the GIEMS-D3-based WL estimations toward the altimetry data, using a second-order polynomial fit, at the Solimoes station 1.5. Each point is monthly data, from January 2003 to December 2007. The second-order polynomial is given by $\mathrm{WL}=19.62-0.65 \times x_{1}+0.03 \times x_{2}^{2}$.

or in the calibration model). More evaluation will be necessary for future studies.

Overall, the results show the following:

- The information carried out by the GIEMS-D3 WL estimates goes beyond the seasonality, and it also includes a monthly and interannual variability (i.e., with a correlation equal to 0.62 ).

- With the help of the calibration, the two WL estimations (from topography or altimetry) are more coherent with each other. This result makes it easier to assimilate both datasets into a hydrological model. The exploitation of the GIEMS-D3/altimetry synergy should increase the available information content.

- In addition, the calibration scheme could also be used to make the two estimates (GIEMS-D3 and altimetry) closer to the WL of a hydrological model. The use of a neural network calibration of retrieved surface variables to facilitate its assimilation into a surface model was suggested for instance for soil moisture in Aires et al. (2005).

- But some additional evaluation would be necessary to validate this model.

Table 1 gives WL comparison statistics over seven locations (Fig. 7) in the Amazon basin. Correlations are estimated for the original/calibrated WL estimates, for the raw and the anomaly data (i.e., calculated by subtracting the 5-yr mean monthly values from the monthly time series). In general, the correlation between the raw 

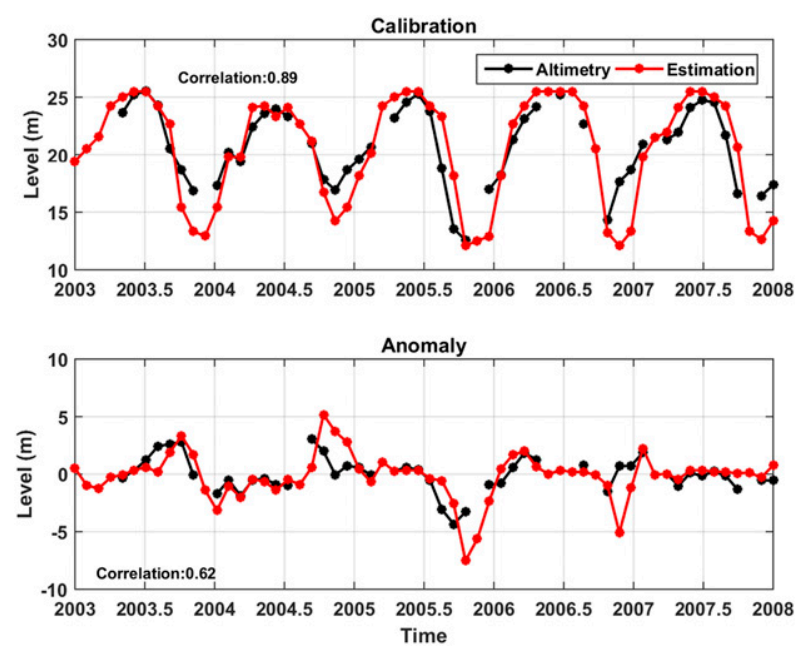

FIG. 6. Time series of the WL calibrated estimations over the Solimoes station 1.5 (see Table 1), compared to altimetry, from January 2003 to December 2007. (top) GIEMS-D3-based WL estimate after calibration. (bottom) WL anomalies, which are calculated as anomaly $=$ actual value - mean seasonal value (climatology). The correlation coefficient is also indicated. The gaps are the missing data from altimetry.

WL estimation and the altimetry measurements is very good. For example, it is around $85 \%$ in the Solimoes River and $88.8 \%$ in the Xingu River. However, results can be lower than $80 \%$ in some regions. In fact, the GIEMS-D3 data can have some deficiencies over thin rivers (GIEMS inundation fraction is less reliable for inundation fractions $\leq 10 \%$ ), highly inundated areas (GIEMS-D3 less reliable for fractions greater than $90 \%$ ), or flat regions where the downscaling scheme of GIEMS-D3 is less reliable since hydrology is less dependent on topography. These
GIEMS-D3 limitations can impact these correlation values, among other reasons. Thus, the calibration step can partially correct some of these errors in the WL estimations.

With the calibration step, the improvement can be significant in some locations: from 0.89 to 0.92 for the Wingu station 1.1, and from 0.72 to 0.79 for the Negro station 1.4. If the calibration was only linear, the correlation would not be increased (i.e., invariance of the correlation by linear transform), so the nonlinear character of the calibration (Fig. 5) is an interesting feature correcting more than the bias (PDFs can be changed by a nonlinear transform). In particular, extreme cases are important for RD, and a nonlinear model should better handle these situations. In general, non-Gaussian distributions would benefit from a nonlinear calibration process. As expected, when considering the anomaly values, the correlation rate decreases because the interannual variability is a second-order variability compared to the seasonality. However, some locations (stations 1.1, 1.4, 1.6, and 1.7) still show very significant correlations ranging from 0.6 to 0.7 , which means that the WL estimate has seasonality information as well as interannual variation information. It would be useful to assimilate the GIEMS-D3 WL in a model to capture part of the interannual hydrological variability. As in any other assimilation experiment, the uncertainties of the model and the WL observations should be characterized to balance the weight of these two sources of information.

Overall, there are several sources of uncertainty in the GIEMS-D3-based WL: GIEMS uncertainty, the GIEMS-D3 downscaling, the preprocessing step to provide higher coherency with the DEM, DEM errors, WL estimation on the water edges, and finally WL interpolation. All

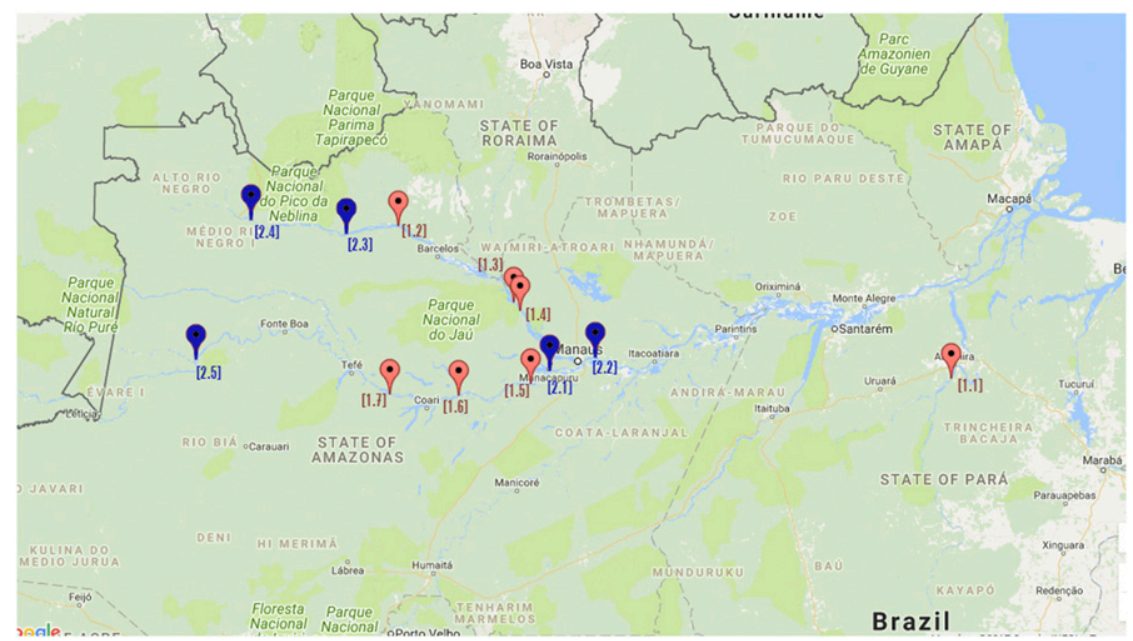

FIG. 7. Google Earth map indicating the location of the sites used for validation over the Amazon basin: the seven red stations for WL and the five blue stations for WVC. 
TABLE 2. Correlation between the GIEMS-D3 WVC estimates (original, season, and anomalies) and the GRACE groundwater storage.

\begin{tabular}{lcccccc}
\hline \hline & & & & $\begin{array}{c}\text { Water } \\
\text { volume } \\
\text { change }\end{array}$ & $\begin{array}{c}\text { WVC } \\
\text { season }\end{array}$ & $\begin{array}{c}\text { WVC } \\
\text { anomaly }\end{array}$ \\
\hline 2.1 & Amazonas & $-3.31^{\circ}$ & $-60.61^{\circ}$ & 0.88 & 0.91 & 0.73 \\
2.2 & Amazonas & $-3.06^{\circ}$ & $-59.65^{\circ}$ & 0.88 & 0.94 & 0.74 \\
2.3 & Negro & $-0.48^{\circ}$ & $-64.83^{\circ}$ & 0.82 & 0.92 & 0.69 \\
2.4 & Negro & $-0.20^{\circ}$ & $-66.80^{\circ}$ & 0.77 & 0.79 & 0.61 \\
2.5 & Amazonas & $-3.10^{\circ}$ & $-67.93^{\circ}$ & 0.86 & 0.86 & 0.70 \\
\hline
\end{tabular}

these sources of uncertainty would require a thorough analysis in the future, in particular, if this process is to be extended to other regions.

\section{b. WVC evaluation using gravimetry measurements from GRACE}

Table 2 presents the correlations between the WVCs calculated in section $3 \mathrm{c}$ and the GRACE data (section 2d) in an area of $200 \times 200$ pixels. Although GRACE data spatial resolution is much higher than the $200 \times$ 200 pixel box (around $325 \mathrm{~km}^{2}$ ), we represent these two datasets in the same figure to compare only their dynamics (i.e., time variations, but not absolute values). We expect not a perfect match between these dynamics, but a partial correlation among them. These comparisons are made on the raw WVC, its season (the 12 monthly mean values averaged over the whole period), and the WVC anomalies. Good comparison statistics can be observed for the five locations (see blue dots in Fig. 7): WVC correlations range from 0.77 to 0.88 . This range increases to $0.79-0.94$ for the WVC seasonality and WVC anomalies keep satisfactory correlations from 0.61 to 0.74 . These results show that the GIEMS-D3-based WVC follows well the GRACE seasonality and include useful interannual information.

\section{c. RD evaluation using in situ measurements}

\section{1) Preliminary ANALysis}

Since the SWE is the original information among the available predictors (SWE, WL, WVC, and RW), a scatterplot between the SWE and RD is represented in Fig. 8 to investigate their relationship, for the raw (left) and the anomaly (right) data. The dots in red correspond to the months during the decreasing water level (from maximal to minimal RD), and the points in blue to the months during the increasing waters (from minimal to maximal RD). A quadratic relationship links the raw data, and a simple linear relationship links the anomalies. The increasing and decreasing waters have different ranges of variability for the raw data, but a single quadratic relationship appears to be enough to describe the two cases. Therefore, a single model will be built in the following for both of them. These scatterplots illustrate well the simplicity of relationships between the two variables, and the type of RD estimation quality that can be obtained with this type of approach.

As a preliminary analysis of the information content of the four predictors (SWE, WL, WVC, and RW) to predict RD, we first measure some simple statistics between the predictors and the in situ RD in the first column of Table 3, for the Manacapuru station. Three diagnostics are represented: the correlations, the root-mean-square error (RMSE; $10^{4} \mathrm{~m}^{3} \mathrm{~s}^{-1}$ ), and the normalized RMSE (NRMSE; \%). The RMSE is given by
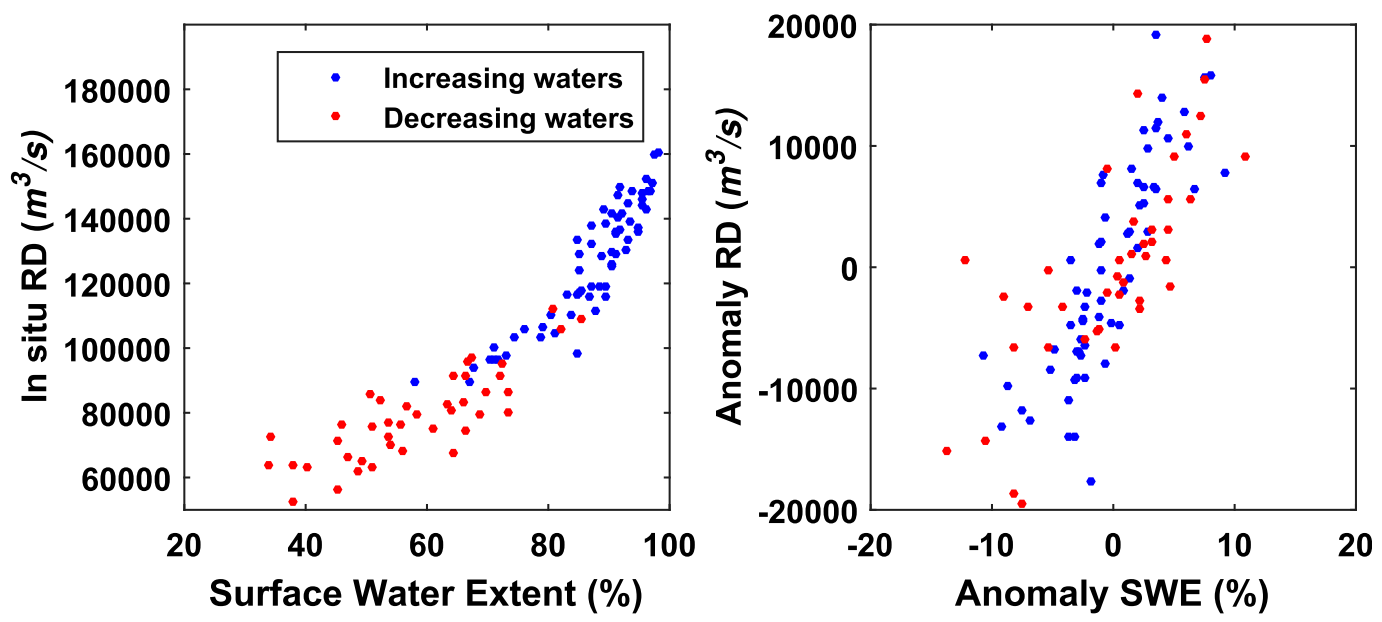

FIG. 8. Scatterplot between the RD and SWE at the Manacapuru station, for (left) raw and (right) anomaly data, from 1998 to 2007, for the increasing water months (blue) and the decreasing water months (red). 
TABLE 3. Correlation (COR), RMSE $\left(10^{4} \mathrm{~m}^{3} \mathrm{~s}^{-1}\right)$, and NRMSE (\%) between the in situ RD and the linear and the neural network RD estimation from the four predictors, for all raw data (top part) and anomalies (bottom part), from 1998 to 2007, over the Manacapuru station. The values in bold indicate the best combination of predictors for river discharge estimation.

\begin{tabular}{|c|c|c|c|c|c|c|c|c|c|c|}
\hline \multirow{3}{*}{$\begin{array}{l}\text { Correlation between } \\
\text { in situ RD and } \\
\\
\text { Predictors }\end{array}$} & \multicolumn{9}{|c|}{ Linear RD prediction } & \multirow[b]{3}{*}{$\mathrm{SWE}+\mathrm{WL}+\mathrm{WVC}$} \\
\hline & \multirow[b]{2}{*}{ SWE } & \multirow[b]{2}{*}{ WL } & \multirow[b]{2}{*}{ WVC } & \multirow[b]{2}{*}{ RW } & \multicolumn{3}{|c|}{ SWE $+\cdots$} & \multicolumn{2}{|c|}{$\mathrm{SWE}+\mathrm{WL}+\cdots$} & \\
\hline & & & & & $\mathrm{WL}$ & WVC & RW & WVC & RW & \\
\hline \multicolumn{11}{|c|}{ Raw data } \\
\hline COR & 0.94 & 0.89 & 0.92 & 0.90 & 0.95 & 0.94 & 0.94 & 0.95 & 0.94 & 0.97 \\
\hline RMSE & 0.67 & 1.22 & 0.89 & 1.11 & 0.56 & 0.67 & 0.67 & 0.56 & 0.67 & 0.33 \\
\hline NRMSE & 6.2 & 11.3 & 8.3 & 10.3 & 5.2 & 6.2 & 6.2 & 5.2 & 6.2 & 3.1 \\
\hline \multicolumn{11}{|c|}{ Anomalies } \\
\hline COR & 0.78 & 0.60 & 0.75 & 0.64 & 0.82 & 0.80 & 0.79 & 0.83 & 0.82 & 0.84 \\
\hline RMSE & 0.19 & 0.34 & 0.21 & 0.31 & 0.15 & 0.17 & 0.18 & 0.14 & 0.15 & 0.13 \\
\hline NRMSE & 17.4 & 31.7 & 23.1 & 28.8 & 14.5 & 17.4 & 17.4 & 14.5 & 17.4 & 8.6 \\
\hline
\end{tabular}

$$
\mathrm{RMSE}=\sqrt{\frac{1}{N} \sum_{n=1}^{N}\left[Q_{r}(n)-Q_{o}(n)\right]^{2}},
$$

where $Q_{r}(n)$ and $Q_{o}(n)$ are the rated and reference discharges at the same time, and $n$ is the total number of samples. The NRMSE is given by

$$
\mathrm{NRMSE}=100 \times \frac{\sqrt{\frac{1}{N_{n}} \sum_{n=1}^{N}\left[Q_{r}(n)-Q_{o}(n)\right]^{2}}}{Q_{\min }-Q_{\max }},
$$

where $Q_{\min }$ and $Q_{\max }$ are the minimum and maximum discharges in the observed series. They are computed for the raw data (top part) and the anomalies (bottom part).

The SWE provides the best fit with the RD (94\%), and the WL has the least individual correlation (0.89). For the anomalies, the correlations are reduced, of course, but the information content is still high: for example, a 0.78 correlation with the SWE. The NRMS indicates the same hierarchy of predictors.

\section{2) EstimAting RESUlts}

Stepwise linear regression with the four predictors (SWE, WL, WVC, and RW) is applied to define the hierarchy of predictors for the RD: each predictor is first used individually in the regression model, to predict the in situ RD. Once the best predictor is chosen, each couple of variables is tested and the best couple is selected. This procedure is performed until the hierarchy of the four predictors is obtained: SWE, WL, WVC, and RW. The results are provided in the remaining of Table 3. It can be seen that the addition of RW as a predictor does not improve the results, so it is discarded in the following. The comparison of the linear and NN models can be done on the last two columns of Table 3 and plotted in Fig. 9. We can see that the correlation increases from 0.95 to 0.97 for the raw data when using the $\mathrm{NN}$ model instead of the linear regression. A $2 \%$ increase could appear not significant, but at this high level of correlation, it is a rather significant improvement. Furthermore, the NRMS decreases from 5.2\% to $3.1 \%$, which is largely significant. For the anomaly data, the use of a $\mathrm{NN}$ increases the correlation from 0.83 to 0.84 only, but the NRMS decreases from $14.5 \%$ to $8.6 \%$. Therefore, in the following, we will use the NN model to estimate the RD.

To test the quality of these results, we compared them to previous comparable studies. When using only one predictor, Paris et al. (2016) found a NRMSE from $6.4 \%$ to $19.8 \%$ in the Amazon region, our results from $3.07 \%$ to $11.33 \%$ seem satisfactory. In addition, Tourian et al. (2017) and Tarpanelli et al. (2018) did a study over the Niger, but the results can still be compared: the relative RMSE is about $12 \%$ in Tourian et al. (2017), and in Tarpanelli et al. (2018), the correlation is around 0.9 .

To check the robustness of the NN results and the overtraining issue, we evaluate the model in the training ( $80 \%$ or 8 years) and test (remaining $20 \%$ ) datasets over the raw and the anomaly data (Table 4). The correlations in the training data are quite similar to the ones in the test data (0.97 and 0.95 on average), so the generalization ability (i.e., performing well on data not used in training) of the NN model for RD appears satisfactory. This result is also true for the anomaly data ( 0.83 and 0.84 on average).

In short, these experiments conclude that a simple statistical model (i.e., an NN with SWE, WL, and WVC as inputs) is able to predict well the RDs at the monthly scale based on the simple surface hydrological information that can be measured from space. 

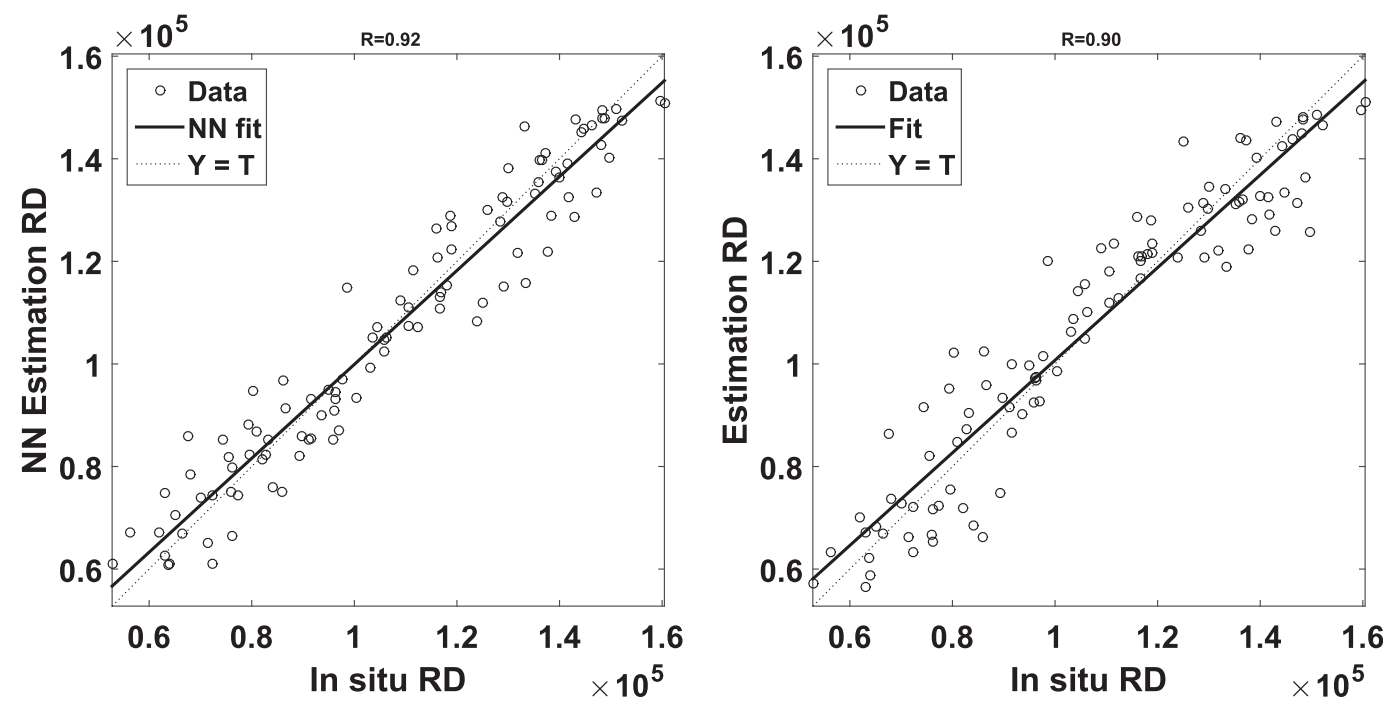

FIG. 9. Estimated vs in situ RD $\left(\mathrm{m}^{3} \mathrm{~s}^{-1}\right)$ for the (left) linear model and (right) NN models, over the Manacapuru station, from 1998 to 2007 with 120 samples $(N=120)$. Both models use three predictors (SWE, WL, WVC). Correlation between estimated and in situ data is also provided.

\section{Conclusions and perspectives}

This study was conducted over a case study over the Amazon region. It has shown that for large rivers, the strategy that we proposed to monitor surface water extend can bring valuable information for river monitoring. Now this approach needs to be tested over other environments to extend the validity of our conclusions. We developed methodologies (i.e., the hypsographic and histogram-cutoff approaches, combined with a spatial interpolation scheme) to determine the WL that uses the high-resolution GIEMS-D3 SWE and HydroSHEDS data. The WVC was then estimated with a reasonable correlation with other measurements, together with the RW. Finally, the RD was estimated using three predictors (SWE, WL, and WVC) using a NN statistical model calibrated on in situ measurements. Although the RD can be estimated from hydrological models, we aimed here for a simpler datadriven approach that does not require extensive ancillary information on the considered river. The proposed method can be applied to provide long time series of RD estimates. However, the study is done over the Amazon River (i.e., the largest river by discharge volume of water in the world) and worked at a monthly scale. Thus, additional tests are now required at higher temporal scale and in other rivers, including smaller ones.

Our study has also shown the benefits of combining the GIEMS-D3 WLs with other data (e.g., topography) in complement to WLs from altimetry. We first demonstrated the potential of SWE measured by satellite, which is not only applicable to GIEMS-D3, but to other past, present, or future high-resolution instruments (e.g., Landsat, MODIS, SAR, or SWOT data). Altimetry data are not available continuously in time (as shown in the gaps in Fig. 6), at the global scale, over long time records. On the other hand, GIEMS-D3 will soon have about a 30-yr time record. Thus, there are advantages and drawbacks to each source of information, and merging them appears to be a valuable strategy.

There are numerous perspectives for this work, on the technical level as well as for new applications. We list below the extension of this work that we intend to conduct in future studies:

TABLE 4. Correlation score of the NN estimates and the in situ RDs (raw and anomaly values), over the training and the test datasets, for the Manacapuru station. Statistics are provided for the 20 members of the Monte Carlo simulation, together in the right column with their averaged values with associated standard deviation as a proxy of correlation uncertainty.

\begin{tabular}{llcccccr}
\hline \hline & Dataset & Test 1 & Test 2 & Test 3 & $\ldots$ & Test 20 & Averaged value \pm Std dev \\
\hline \multirow{2}{*}{ Raw } & Training & 0.97 & 0.96 & 0.97 & $\ldots$ & 0.97 & $0.97 \pm 0.01$ \\
\multirow{3}{*}{ Anomaly } & Test & 0.96 & 0.99 & 0.93 & $\ldots$ & 0.99 & $0.95 \pm 0.06$ \\
& Training & 0.85 & 0.76 & 0.86 & $\ldots$ & 0.86 & $0.83 \pm 0.05$ \\
& Test & 0.87 & 0.90 & 0.74 & $\ldots$ & 0.85 & $0.84 \pm 0.06$ \\
\hline
\end{tabular}


- Extension to other environments: In the future, we would like to extend this proof-of-concept study to many different rivers, with different sizes and hydrological regimes. This will allow us to better assess the range of validity of the methodology, provide some uncertainties, and identify the basin where this method is suitable.

- Time resolution: This study was performed at the monthly scale because this is the time resolution GIEMS-D3 is provided at. If SWE were provided at a higher temporal scale (weekly or even daily), the methods would have to be adapted but similar approaches could be used.

- Uncertainty characterization: In the histogram-cutoff approach, the two elevation distributions (water and nonwater pixels) are in general differentiable. However, problems could appear if the region is very flat (which can be the case over Amazon). Thus, in the future, we will try to establish a statistical hypothesis testing (differentiation of the two distributions) to avoid such situations. In addition, we will design an uncertainty diagnostic to alert when the distributions are too close.

- Link with the SWOT mission: The NASA/CNES SWOT mission, planned for launch in 2021, is specifically designed to provide good high-spatial resolution (i.e., river larger than $100 \mathrm{~m}$ and water area above $250 \mathrm{~m} \times 250 \mathrm{~m}$ ) and good temporal sampling (21 days repeat) of the extent (and elevation) of continental surface waters (Prigent et al. 2016; Biancamaria et al. 2016) thanks to an interferometric Ka-band radar (Desai et al. 2018). Part of the work done here could be used with the SWOT water mask.

- There are two main advantages of using high-spatialresolution maps from SWOT instead of GIEMS-D3: 1) no need to downscale GIEMS since SWOT estimates will be direct observations at the right spatial resolution and 2) the data would be in real time, thus no need to wait for the GIEMS estimate or its downscaling. However, we do not know if SWOT will be able to detect surface water beneath vegetation (so far, only GIEMS and GIEMS-D3 seem to focus on this aspect; Aires et al. 2018). Therefore, additional tests would be necessary.

- SWOT river discharge estimates could be used as "ground truth" to calibrate our model. In this case, we would avoid the use of in situ river discharge so the methodology could be used in ungauged locations.

- When enough SWOT images are available, we could define a new global and high-resolution floodability index that could be used to downscale GIEMS. GIEMS-D3 would then become coherent with SWOT.
And using it with our RD model over the full GIEMS record would extend, back in time, the RD estimated by SWOT (starting in 2021 only).

- Newer GIEMS/GIEMS-D3: GIEMS-D3 will soon be reprocessed using an improved topography (Yamazaki et al. 2017) and improved GIEMS. The new GIEMS version will be extended in time, from 2007 to present, and to years antecedent to 1993 . The time series length is expected to reach almost 30 years. Furthermore, some corrections were made in the retrieval scheme so that overestimation of inundation (in particular in Asia) will be corrected. This will have an impact on the quality of our hydrological estimates. The overall approach requires to be tested over various environments worthwhile.

- Improvement of the RD model: The statistical model for the RD estimate could be improved too, for instance, by adding more a priori or temporal information in the predictors. Our current model is defined at the monthly time scale. For increased time resolutions (hourly or daily), it would be necessary to introduce to the model our diagnostics (SWE, WL, WVC, and RW) at time $t, t-\Delta t, t-2 \Delta t$, etc. because memory effects can be important for the RD estimation. The location of the area that best predicts the RD in one measurement station could be optimized. Some works have shown for instance that areas with changes of river direction are important because sand deposits and erosion make the land flatter with a better characterization of the WL and RD. Uncertainty estimates could be derived from the RD NN-retrieval algorithms (Aires 2004; Aires et al. 2004), this would facilitate: the use of the derived RD in hydrological studies, and the assimilation of the RD estimates in hydrological models. Another benefit from the SWOT mission is that with its repeating observations on time, we could obtain better bathymetry information in particular during low-flow events.

- Temporal extension of the GRDC record: Since we used a statistical model to estimate the RD, one constraint is to have access to some in situ RD measurements to calibrate the models. Our approach can, therefore, be applied in GRDC RD stations that have enough temporal overlap with GIEMS-D3 to calibrate the model, and with a discharge and drainage area that is large enough so that GIEMS/GIEMS-D3 estimates are reliable. Once the RD models are calibrated, the RD can be estimated over the whole GIEMS-D3 period, including dates when no in situ data are available. Since the GIEMS dataset will soon be extended over time, our method could coherently interpolate/extrapolate the in situ GRDC record over the three to four decades of passive microwave observation record. Once all the 
methodological developments are done, an automatic processing scheme could be developed to estimate RD in all the stations included in the GRDC database over a time record of more than 30 years. This improvement would have numerous applications, in particular, to study the water cycle at the global scale (Aires 2014; Munier et al. 2014).

- Extension on ungauged rivers: The SWE was here used to estimate RD over gauged rivers. It is a true challenge to exploit the satellite data over ungauged rivers (Gleason et al. 2014). This work was attempted for instance by using a river characterization and an "at-many-stations hydrologic geometry" approach (Gleason and Smith 2014; Gleason et al. 2014). In our approach, a reference RD is required in order to calibrate the algorithms. We could use the estimates from a model (Yamazaki et al. 2011) if its quality is good enough, to have a proxy of the RD at the global scale. Our retrieved times series of RD would then be controlled by the satellite observations (intraseason to interannual variations), but the bias and scaling of these values would be dependent on the model. This drawback could actually benefit the assimilation of observations in the model (Aires et al. 2005). However, this task is a challenging one: Previous global intercomparison studies on satellite-based discharge estimates (see reference below) have shown the spatial variability in algorithm performance and have suggested that a single algorithm will not be able to accurately estimate river discharge on a global scale (Durand et al. 2016). Taking into account local specificities is, therefore, a necessity in the RD modeling.

Acknowledgments. We thank the USTH (University of Science and Technology of Hanoi) and in particular Yannick Giraud-Héraud, the coordinator of the French USTH program, for helping Dinh Thi Lan Anh internship in France, at LERMA (Laboratoire d'Études du Rayonnement et de la Matière en Astrophysique et Atmosphères). We are also thankful to Catherine Prigent, Fabrice Papa, Luca Brocca, and Angelica Tarpanelli for fruitful discussions.

\section{REFERENCES}

Aires, F., 2004: Neural network uncertainty assessment using Bayesian statistics with application to remote sensing: 1 . Network weights. J. Geophys. Res., 109, D10303, https://doi.org/ 10.1029/2003JD004173.

_ 2014: Combining datasets of satellite-retrieved products. Part I: Methodology and water budget closure. J. Hydrometeor., 15, 1677-1691, https://doi.org/10.1175/JHM-D-13-0148.1.

- C. Prigent, and W. B. Rossow, 2004: Neural network uncertainty assessment using Bayesian statistics with application to remote sensing: 2. Output errors. J. Geophys. Res., 109, D10304, https://doi.org/10.1029/2003JD004174.

,$- \ldots$, and -2005 : Sensitivity of satellite microwave and infrared observations to soil moisture at a global scale: 2 . Global statistical relationships. J. Geophys. Res., 110, D11103, https://doi.org/10.1029/2004JD005094.

— F. Papa, and C. Prigent, 2013: A long-term, high-resolution wetland dataset over the Amazon basin, downscaled from a multiwavelength retrieval using SAR data. J. Hydrometeor., 14, 594-607, https://doi.org/10.1175/JHM-D-12-093.1.

$-\longrightarrow,-$, J.-F. Crétaux, and M. Bergé-Nguyen, 2014: Characterization and space-time downscaling of the inundation extent over the inner Niger Delta using GIEMS and MODIS data. J. Hydrometeor., 15, 171-192, https://doi.org/ 10.1175/JHM-D-13-032.1.

, L. Miolane, C. Prigent, B. Pham, E. Fluet-Chouinard, B. Lehner, and F. Papa, 2017: A global dynamic long-term inundation extent dataset at high spatial resolution derived through downscaling of satellite observations. J. Hydrometeor., 18, 1305-1325, https://doi.org/10.1175/JHM-D-16-0155.1.

- C. Prigent, E. Fluet-Chouinard, D. Yamazaki, F. Papa, and B. Lehner, 2018: Comparison of visible and multi-satellite global inundation datasets at high-spatial resolution. Remote Sens. Environ., 216, 427-441, https://doi.org/10.1016/j.rse.2018.06.015.

Ashmore, P., and E. Sauks, 2006: Prediction of discharge from water surface width in a braided river with implications for ata-station hydraulic geometry. Water Resour. Res., 42, 79-11, https://doi.org/10.1029/2005WR003993.

Biancamaria, S., D. P. Lettenmaier, and T. M. Pavelsky, 2016: The SWOT mission and its capabilities for land hydrology. Surv. Geophys., 37, 307-337, https://doi.org/10.1007/s10712-015-9346-y.

Bjerklie, D. M., S. Lawrence Dingman, C. J. Vorosmarty, C. H. Bolster, and R. G. Congalton, 2003: Evaluating the potential for measuring river discharge from space. J. Hydrol., 278, 17-38, https://doi.org/10.1016/S0022-1694(03)00129-X.

Brakenridge, G. R., S. V. Nghiem, E. Anderson, and S. Chien, 2005: Space-based measurement of river runoff. Eos, Trans. Amer. Geophys. Union, 86, 185-188, https://doi.org/10.1029/ 2005EO190001.

,,--- , and R. Mic, 2007: Orbital microwave measurement of river discharge and ice status. Water Resour. Res., 43, W04405, https://doi.org/10.1029/2006WR005238.

Calmant, S., J. S. da Silva, D. M. Moreira, F. Seyler, C. K. Shum, J.-F. Crétaux, and G. Gabalda, 2013: Detection of Envisat RA2/ICE-1 retracked radar altimetry bias over the Amazon basin rivers using GPS. Adv. Space Res., 51, 1551-1564, https:// doi.org/10.1016/j.asr.2012.07.033.

Cretaux, J., and Coauthors, 2011: SOLS: A lake database to monitor in the Near Real Time water level and storage variations from remote sensing data. Adv. Space Res., 47, 1497-1507, https:// doi.org/10.1016/j.asr.2011.01.004.

Desai, S., L.-L. Fu, S. Cherchali, and P. Vaze, 2018: Surface Water and Ocean Topography Mission (SWOT) Project science requirements document. Tech. Rep. JPL D-61923, Jet Propulsion Laboratory, California Institute of Technology, 29 pp., https:// swot.jpl.nasa.gov/docs/D-61923_SRD_Rev_B_20181113.pdf.

Durand, M., and Coauthors, 2016: An intercomparison of remote sensing river discharge estimation algorithms from measurements of river height, width, and slope. Water Resour. Res., 52, 4527-4549, https://doi.org/10.1002/2015WR018434.

Fluet-Chouinard, E., B. Lehner, L.-M. Rebelo, F. Papa, and S. K. Hamilton, 2015: Development of a global inundation map at high spatial resolution from topographic downscaling of 
coarse-scale remote sensing data. Remote Sens. Environ., 158, 348-361, https://doi.org/10.1016/j.rse.2014.10.015.

Gleason, C. J., and L. C. Smith, 2014: Toward global mapping of river discharge using satellite images and at-many-stations hydraulic geometry. Proc. Natl. Acad. Sci. USA, 111, 4788-4791, https:// doi.org/10.1073/pnas.1317606111.

$\longrightarrow$, _ - , and J. Lee, 2014: Retrieval of river discharge solely from satellite imagery and at-many-stations hydraulic geometry: Sensitivity to river form and optimization parameters. Water Resour. Res., 50, 9604-9619, https://doi.org/10.1002/2014WR016109.

Hornik, K., M. Stinchcombe, and H. White, 1990: Universal approximation of an unknown mapping and its derivatives using multilayer feedforward networks. Neural Networks, 3, 551-560, https://doi.org/10.1016/0893-6080(90)90005-6.

Landerer, F. W., and S. C. Swenson, 2012: Accuracy of scaled GRACE terrestrial water storage estimates. Water Resour. Res., 48, W04531, https://doi.org/10.1029/2011WR011453.

Lehner, B., K. Verdin, and A. Jarvis, 2008: New global hydrography derived from spaceborne elevation data. Eos, Trans. Amer. Geophys. Union, 89, 93-94, https://doi.org/10.1029/ 2008EO100001.

Munier, S., F. Aires, S. Schlaffer, C. Prigent, F. Papa, P. Maisongrande, and M. Pan, 2014: Combining data sets of satellite-retrieved products for basin-scale water balance study: 2. Evaluation on the Mississippi Basin and closure correction model. J. Geophys. Res. Atmos., 119, 12 100-12116, https://doi.org/10.1002/2014JD021953.

Papa, F., F. Frappart, A. Güntner, C. Prigent, F. Aires, A. C. V. Getirana, and R. Maurer, 2013: Surface freshwater storage and variability in the Amazon basin from multi-satellite observations, 1993-2007. J. Geophys. Res. Atmos., 118, 11951-11 965, https:// doi.org/10.1002/2013JD020500.

Paris, A., and Coauthors, 2016: Stage-discharge rating curves based on satellite altimetry and modeled discharge in the Amazon basin. Water Resour. Res., 52, 3787-3814, https://doi.org/10.1002/ 2014WR016618.

Pekel, J.-F., A. Cottam, N. Gorelick, and A. S. Belward, 2016: High-resolution mapping of global surface water and its longterm changes. Nature, 540, 418-422, https://doi.org/10.1038/ nature20584.

Prigent, C., E. Matthews, F. Aires, and W. B. Rossow, 2001: Remote sensing of global wetland dynamics with multiple satellite data sets. Geophys. Res. Lett., 28, 4631-4634, https://doi.org/10.1029/ $2001 G L 013263$.

, F. Papa, F. Aires, W. B. Rossow, and E. Matthews, 2007: Global inundation dynamics inferred from multiple satellite observations, 1993-2000. J. Geophys. Res., 112 D12107, https://doi.org/10.1029/2006JD007847.

, D. P. Lettenmaier, F. Aires, and F. Papa, 2016: Toward a high-resolution monitoring of continental surface water extent and dynamics, at global scale: From GIEMS (Global Inundation Extent from Multi-Satellites) to SWOT (Surface Water
Ocean Topography). Surv. Geophys., 37, 339-355, https:// doi.org/10.1007/s10712-015-9339-x.

Rumelhart, D. E., G. E. Hinton, and R. J. Williams, 1986: Learning internal representations by error propagation. Parallel Distributed Processing: Explorations in the Microstructure of Cognition, Vol. I, MIT Press, 567 pp.

Santos da Silva, J., S. Calmant, F. Seyler, O. C. Rotunno Filho, G. Cochonneau, and W. J. Mansur, 2010: Water levels in the Amazon basin derived from the ERS 2 and ENVISAT radar altimetry missions. Remote Sens. Environ., 114, 2160-2181, https://doi.org/10.1016/j.rse.2010.04.020.

Smith, L. C., 1997: Satellite remote sensing of river inundation area, stage, and discharge: A review. Hydrol. Processes, 11, 1427-1439, https://doi.org/10.1002/(SICI)1099-1085(199708) 11:10<1427::AID-HYP473>3.0.CO;2-S.

- B. L. Isacks, R. R. Forster, A. L. Bloom, and I. Preuss, 2007: Estimation of discharge from braided glacial rivers using ERS 1 synthetic aperture radar: First results. Water Resour. Res., 31, 1325-1329, https://doi.org/10.1029/95WR00145.

Tapley, B. D., S. Bettadpur, M. Watkins, and C. Reigber, 2004: The gravity recovery and climate experiment: Mission overview and early results. Geophys. Res. Lett., 31, L09607, https:// doi.org/10.1029/2004GL019920.

Tarpanelli, A., L. Brocca, T. Lacava, F. Melone, T. Moramarco, M. Faruolo, N. Pergola, and V. Tramutoli, 2013: Toward the estimation of river discharge variations using MODIS data in ungauged basins. Remote Sens. Environ., 136, 47-55, https:// doi.org/10.1016/j.rse.2013.04.010.

_ , E. Santi, M. J. Tourian, P. Filippucci, G. Amarnath, and L. Brocca, 2018: Daily river discharge estimates by merging satellite optical sensors and radar altimetry through artificial neural network. IEEE Trans. Geosci. Remote Sens., 57, 329-341, https://doi.org/10.1109/TGRS.2018.2854625.

Tourian, M. J., C. Schwatke, and N. Sneeuw, 2017: River discharge estimation at daily resolution from satellite altimetry over an entire river basin. J. Hydrol., 546, 230-247, https://doi.org/ 10.1016/j.jhydrol.2017.01.009.

Wahl, K. L., W. O. Thomas Jr., and R. M. Hirsch, 1995: Streamgaging program of the U.S. Geological Survey. USGS Circular 1123, https://pubs.usgs.gov/circ/circ1123/.

Yamazaki, D., S. Kanae, H. Kim, and T. Oki, 2011: A physically based description of floodplain inundation dynamics in a global river routing model. Water Resour. Res., 47, W04501, https://doi.org/10.1029/2010WR009726.

_ M. A. Trigg, and D. Ikeshima, 2015: Development of a global $\sim 90$ m water body map using multi-temporal Landsat images. Remote Sens. Environ., 171, 337-351, https://doi.org/10.1016/ j.rse.2015.10.014.

_ , and Coauthors, 2017: A high-accuracy map of global terrain elevations. Geophys. Res. Lett., 44, 5844-5853, https://doi.org/ 10.1002/2017GL072874. 